\title{
CORPO E VULNERABILIDADE: CAMINHOS DA TEOLOGIA PÓS-MODERNA
}

\author{
CORPS ET VULNÉRABILITÉ: \\ CHEMINS DE LA THÉOLOGIE POSTMODERNE
}

\author{
RENÉ DENTZ ${ }^{(*)}$ \\ VICENTE de PAULA FERREIRA ${ }^{(* *)}$
}

\begin{abstract}
RESUMO
Ao tomar o evento cristão como testemunho do feliz encontro entre Deus e homem, na pessoa de Jesus, a Teologia tem a contínua tarefa de trazer tal iluminação para o diálogo com cada época e suas realidades. E, em certo sentido, mesmo com suas limitações, que não são poucas, a pós-modernidade tem seus apelos especiais para quem procura aprofundar o humanismo cristão. Como proclamar a misericórdia infinita de Deus em tempos de vulnerabilidade corpórea? De fato, o que antes, no declínio da modernidade poderia se configurar como declínio racional, uma passagem da razão forte para a razão fraca, hoje as marcas da fragilidade humana estão inscritas em seu próprio corpo. Caso essa vulnerabilidade configure-se como encontro aberto com a finitude, ultrapassando estruturas de egoísmo, haverá, então, a possibilidade de se inscrever como lugar privilegiado da teologia pós-moderna. Uma importante contribuição à teologia na contemporaneidade foi a de Paul Ricoeur, através de sua abordagem sobre a narrativa.
\end{abstract}

PALAVRAS-CHAVE: Corpo. Vulnerabilidade. Encarnação. Pós-Modernidade. Narratividade.

\section{RÉSUMÉ}

En prenant l'événement chrétien comme témoin de la rencontre heureuse entre Dieu et l'homme, en la personne de Jésus, la théologie a la tâche continue d'apporter un tel éclairage au dialogue avec chaque saison et leurs réalités. Et, dans un sens, même avec ses limites, qui ne sont pas rares, postmodernité a son attrait particulier pour ceux qui cherchent à approfondir l'humanisme chrétien. Comment proclamer la miséricorde infinie de Dieu dans la vulnérabilité physique des temps? En fait, avant cela, le déclin de la modernité pourrait être configuré comme un déclin rationnel, un passage de la raison forte pour la raison faible, aujourd'hui les

(*) Professor Universitário e Psicanalista. Atualmente realiza pesquisa doutoral na Faculdade Jesuíta de Filosofia e Teologia de Belo Horizonte (FAJE) sobre "Liberdade, Culpa e Perdão" a partir do pensamento do filósofo francês Paul Ricoeur. Autor do livro "O Conceito de Pessoa em Paul Ricoeur" (2010). Membro da Society for Ricoeur Studies (EUA) e da Alalite (Associação Latino-americana de Literatura e Teologia). É Fellow (Pesquisador) do International Institute for Hermeneutics/Freiburg Universität (Alemanha). Desde 2012 apresenta trabalhos em congressos no exterior: 2012 (Università del Salento-Lecce-ITÁLIA), 2013 e 2014 (PUC-Santiago-CHILE), 2015 (Jesuit University Ignatianum-Cracóvia-POLÔNIA), 2016 (Universidad Catolica Argentina-Buenos Aires-ARGENTINA, Universidad Santo Tomás-TunjaCOLÔMBIA e Freiburg Universität-ALEMANHA) e 2017 (Universidade Lusófona-Lisboa-PORTUGAL e Faculté de Paris/Fonds Ricoeur-Paris-FRANÇA). É Membro do Grupo de Pesquisa CAPES "Interfaces da Antropologia na Teologia Contemporânea" na Faculdade Jesuíta de Belo Horizonte; Membro do Grupo de Pesquisa "Direito, Pós-Modernidade e Educação: crítica e hermenêutica", na Universidade Presidente Antônio Carlos de Mariana-MG. E-mail: dentz@hotmail.com.

${ }^{(* *)}$ Pós-doutor pela Faculdade Jesuíta de filosofia e Teologia (FAJE), onde também é membro do grupo de pesquisas Interfaces da Teologia na Antropologia Contemporânea. Possui doutorado e mestrado em Ciências da Religião pela Universidade Federal e Juiz de Fora. Graduação em Teologia pela Faculdade Jesuíta de Filosofia e Teologia (1996) e graduação em Filosofia pela Universidade Federal de Juiz de Fora (1990). É Bispo-auxiliar da Arquidiocese de Belo Horizonte. Membro da Sociedade de Estudos Psicanalíticos de Juiz de Fora. Tem experiência na área de Teologia, Filosofia e Psicanálise. E-mail: pe.vicente@veloxmail.com.br 
marques de la fragilité humaine sont enregistrés dans leur propre corps. Si cette vulnérabilité pour le configurer comme une réunion ouverte avec la finitude, en surmontant les structures de l'égoïsme, il y aura alors en mesure de vous inscrire comme un lieu privilégié de la théologie post-moderne. Une contribution importante à la théologie à l'époque contemporaine est celle de Paul Ricoeur par son approche du récit.

MOTS-CLÉS: Corps. Vulnérabilité. Incarnation. Postmodernité. Narration.

INTRODUÇÃO

A encarnação do logos divino na história desvelou a livre e gratuita autocomunicação de Deus ao homem. Jesus Cristo não é somente Palavra eterna, porém sua totalidade existencial configura a mais profunda liberdade corpórea como horizonte de sentido para cada homem. Levar em conta a concretude histórica supõe entender, por um lado, o corpo humano enquanto matéria radicalmente ferida pela falta e, por outro, marcada por um excesso de sentido que pode ser traduzido como sua dimensão espiritual. É na dinâmica tensão entre corpo de desejo e materialidade carnal que a pessoa humana anseia por vias de construção de uma liberdade que lhe dê sentido.

Num primeiro momento, o presente artigo tratará de elementos dessa vulnerabilidade com alguns pontos epistemológicos e o exemplo de Frida Kahlo. Em seguida, será apresentada a possibilidade de um novo horizonte teológico, sobretudo no contexto latino-americano. Não terá a Teologia da Libertação se ocupado demasiadamente em pensar o pobre enquanto categorial social, olvidando sua ferida mais radical, que se dá num corpo concreto, que possui nome e história? Se a encarnação cristã desvela o sentido sagrado do corpo como morada divina, como anunciar o Evangelho realmente como boa nova para as minorias agredidas em suas diferenças corpóreas? Sem pretensões de respostas a essas perguntas tão atuais, pretende-se, enfim, abrir um diálogo a partir de bases antropológicas com o intuito de verificar novos acenos teológicos. 


\section{VULNERABILIDADE CORPÓREA PÓS-MODERNA}

No declínio da modernidade, o pensamento hermenêutico reconhece a passagem da razão forte, com pretensões de domínio sobre a realidade, para um pensamento enfraquecido, consciente da radicalidade interpretativa, na qual a subjetividade humana está inserida. Para um dos expoentes de tal pensamento, o filósofo Gianni Vattimo, a Pós-Modernidade é a despedida do sentido unitário de história, de progresso, de sexualidade humana. O que se instaura nessa nova época é o pluralismo como tecido social, no qual a vulnerabilidade humana, caso não queira sucumbir-se aos domínios da violência metafísica, deve empenhar-se na construção de uma comunidade mais amiga e laica. Para tal pensamento, não se trata de despedida das experiências religiosas cristãs; no entanto, "se deseja concretizar-se na forma de hospitalidade, a identidade do cristão no diálogo inter-religioso - aplicando o preceito da caridade - pode apenas se reduzir, quase completamente, a um dar ouvidos e palavra aos hóspedes" (VATTIMO, 2004, p. 126).

Se, por um lado, é necessário pensar a presença da religião - de maneira particular do cristianismo como instância que promove a valorização do mundo - de forma que todo o processo de secularização, de algum modo, cumpra sua vocação mais genuína que está fundamentada no mandamento do amor; por outro lado, é tarefa contínua combater toda e qualquer forma de imposição da verdade como domínio e poder. De outro modo, pensar o cristianismo já não mais pelas vias do poder é cumprir sua missão de construção da amizade diante das experiências da finitude humana, iluminando a realidade com a luz da caridade, que faz a dignidade humana construir vias de maturidade. Ou seja,

[...] a filosofia da religião do nosso século é preferencialmente existencial: enquanto São Tomás e a Idade Média pensava em provar a existência de Deus a partir da ordem do mundo, o pensamento religioso moderno procura a prova de Deus sobretudo na precariedade e tragicidade da condição humana (VATTIMO, 1999, p. 84). 
Para o criador do pensamento fraco, há uma estreita relação entre a morte do Deus violento da metafísica, o enfraquecimento do ser e a kênosis cristã. Assim, "a herança cristã que retorna no pensamento fraco é também e, sobretudo, herança do preceito cristão da caridade e de sua recusa da violência" (VATTIMO, 1999, p. 37). Uma das consequências mais importantes para repensar esse nexo entre filosofia enfraquecida e caritas cristã é a defesa das vítimas, que não puderam contar sua história porque foram caladas pela tradição dominante, muitas vezes em nome da verdade. No limiar do declínio do pensamento metafísico, inaugura-se uma nova possibilidade de pensar no enfraquecimento não somente do ponto de vista racional, como do ponto de vista corpóreo dos que viveram ou vivem sem sua dignidade básica: a de ser corpo histórico.

A Pós-Modernidade impacta, assim, de forma decisiva a teologia, ou pelo menos faz a firme interpelação para que resgate a decisiva profissão de fé de que o verbo se fez carne. Algumas questões inquietantes são: como pensar Deus a partir do sujeito fragmentado? Como afirmar e defender a dignidade humana numa época "pós-metafísica”? Chegamos, dessa forma, a uma importante instância do saber teológico pós-moderno, aquela de Sujeito Vulnerável. Esse conceito, bem interpretado, nos permite pensar pelo menos em quatro aspectos da vulnerabilidade: o desencantamento do mundo; a consciência de exclusão vivida; o desmantelamento da onipotência; e, por último, os novos projetos sociopolíticos. Segundo Mendoza:

[...] a partir da assunção da própria vulnerabilidade o sujeito fraco começa a mostrar outro rosto para além da aparência anódina que o etiquetava numa primeira impressão. Assim começa a gênese de uma presença para si mesmo de caráter proativo, marcada pela tomada de distância com respeito aos sistemas de totalidade e sua influência nos mecanismos da própria subjetividade. (MENDOZA, 2011, p. 148).

Desse modo, o desamparo humano desloca-se de sua possível passividade para uma tomada de decisão da finitude como gramática genuinamente existencial. Um não temer a morte como horizonte que impulsiona a vida a se construir, alicerçada numa esperança de gratuidade. Mais ainda, a ousada profecia de que "são precisamente eles, os justos da história, quem nos sustenta na consciência agônica vivida como experiência de viver até o último suspiro. Uma existência niilista enquanto é vivida nos limites de si mesmo." (MENDOZA, 2011, p. 191).

Um exemplo precioso da resistência de um corpo vulnerável é Frida Kahlo. 
Por meio de sua arte, Frida assume as dores de seu corpo próprio. Ou seja, somatiza eventos significativos de sua existência. Seu corpo é uma expressão de sua arte e é a memória dos acontecimentos trágicos de sua vida. Como afirma Deifelt:

\begin{abstract}
A ambiguidade de Frida não é sinônimo de contradição. A sua existência é marcada precisamente pelo limítrofe, pelo fronteiriço. Ela habita nas intersecções: nas fronteiras de seu próprio corpo, que lhe dá prazer e dor; nas fronteiras da relacional idade, com um Diego que ela identifica como seu grande amor e como a grande catástrofe de sua vida; com a arte, que é uma extensão de si mesma, mas que ela mesma não valoriza, até conseguir manter-se financeiramente pela pintura; nas fronteiras de suas próprias convicções políticas, religiosas, culturais e sociais - de todas elas, ela tirava elementos construtivos para uma sociedade mexicana alternativa, mas desencantava-se constantemente com os rumos dos acontecimentos em seu país. (DEIFELT, 2006, p. 33).
\end{abstract}

Com isso, Frida torna-se profetiza de um corpo ao mesmo tempo fragmentado e resistente na sua radical condição erógena e desejante. Mostra que o corpo humano fornece um horizonte de mundo, reflexão e instauração de novos sentidos. É o lugar do prazer e da dor, além de possibilitar ambiguidades e, por isso mesmo, nos tornar "humanos". Ao registrar a memória de sua corporeidade pela pintura, Frida expõe seu horizonte de existência.

No quadro La Venadita, a figura do veado é, a um só tempo, um instrumento através do qual Frida Kahlo pode exprimir sua realidade, seu mundo e ela própria dizendo-se. Forma e conteúdo se misturam. Enquanto é algo fora de si mesma (meio), metáfora, o veado é também a materialização (conteúdo) que fala por si. O veado de Frida é a Frida-veado, e vice-versa. O ser que ocupa o lugar central da pintura, portanto, é uma criação de Frida Kahlo, e é um veado! [...] O veado é a fuga do seu destino, a decisão sobre seu nascimento, a ordenação provisória de sua vida que não tem ordem: começa e termina várias vezes, sobe e desce, gira, dá piruetas, vai para cá e para lá, sacudida, sacudindo-se, acidentando-se. Seu signo não é "câncer”, mas "veado". (MUSSKOPF, 2012, p. 443).

O "veado" de Frida é uma condição, um corpo ferido, que faz parte de um sujeito vulnerável, excluído da filosofia, da teologia, da salvação; enquadrado pela ciência e criminalizado pela sociedade. Dessa forma, a arte de Frida é material importante que respalda aquela convicção psicanalítica de que o corpo humano possui um excesso de sentido, que não pode ser manipulado pela razão e pela ciência. "Isso porque aqui estariam os registros desejante e pulsional do corpo, irredutíveis que seriam ao conceito de organismo.” (BIRMAN, 2001, p. 58).

E nesse sentido, a hermenêutica do pensamento fraco revela-se como 
pensamento dos enfraquecidos, por defender que:

[...] derrubada a ideia de uma racionalidade central da história, o mundo da comunicação generalizada explode como uma multiplicidade de racionalidades locais - minorias étnicas, sexuais, religiosas, culturais ou estéticas - que tomam a palavra, finalmente não mais caladas e reprimidas pela ideia que haja somente uma forma de humanidade verdadeira para realizar, em detrimento de toda a peculiaridade, de toda a individualidade limitada, efêmera, contingente. (VATTIMO, 2000, p. 17).

\section{A CONTRIBUIÇÃO DE RICOEUR À TEOLOGIA PÓS-MODERNA}

Dessa forma, poderíamos afirmar que a possibilidade de uma teologia especulativa estaria morta, dando lugar a uma pura realidade corpórea, inominável em sua vulnerabilidade? Em que sentido o pensador Paul Ricoeur estaria próximo de alguns paradigmas da teologia pós-moderna, servindo-lhe como referencial? Primeiramente é necessário ouvir o que o próprio filósofo diz:

[...] Mas essa destruição da teologia especulativa como ciência dos objetos não implica que o próprio saber objetivo seja absoluto. Ao contrário, saber objetivo é o trabalho do "entendimento" (Verstand) e o "entendimento" não esgota o poder da razão (Vernunft) que permanece a função do Incondicionado. Essa distância, essa tensão entre a "razão" como função do Incondicionado e o "entendimento" como a função do saber condicionado encontra sua expressão na noção de "limite" (Grenze) que Kant não identifica com a da "fronteira" (Schranke). O conceito de "limite" não implica só - nem mesmo originariamente - que nosso saber seja limitado, tenha fronteiras, mas que a busca do incondicionado ponha limites à reivindicação do saber objetivo de tornar-se absoluto. O limite não é um fato, mas um ato. (RICOEUR, 2006, p. 2019).

Da mesma forma que o conflito entre as interpretações objetiva e metafórica é fundamental à significação da metáfora, um conflito entre a reivindicação objetiva do saber e a apresentação poética do Incondicionado precisa ser mantido na linguagem do advento. Trata-se de uma linguagem que se porta como conceito-limite e como apresentação figurativa do Incondicionado. Segundo Ricoeur, a partir de Bultmann, o querigma deve conter o passado de Jesus no tempo presente do Cristo. Se não for assim, corremos o risco de uma interpretação gnóstica. De alguma forma o que possibilita a continuidade da interpretação do evento Jesus Cristo é que sua facticidade possui uma reserva inesgotável de sentido. Excesso que abre as vias possíveis das interpretações e que ao mesmo tempo permanece Inominado:

A paixão pelo possível não implica nenhuma ilusão: sabe que toda ressurreição é uma ressurreição dentre os mortos, que toda criação nova é a despeito da morte. 
Como costumavam dizer os Reformadores, a Ressurreição está escondida sob seu contrário, a Cruz. Com efeito, considerada desse ponto de vista da esperança, a vida não é somente o contrário, mas a negação da morte: essa negação repousa sobre sinais, não sobre provas. Interpreta de uma maneira criativa os sinais da superabundância da vida a despeito da evidência da morte. O "tanto mais" da lei da superabundância não pode abrir mão do "a despeito de", a despeito da morte, que dá à esperança sua lucidez, sua seriedade, sua determinação. De minha parte, direi que a liberdade é a capacidade de viver segundo a lei paradoxal da superabundância, da negação da morte e da afirmação do excesso de sentido sobre o não-sentido em todas as situações desesperadas. (RICOEUR, 2006, p. 105).

Parece que essa suposta irracionalidade gera outro tipo de inteligência. Trata-se de outro tipo de racionalidade, que desafia os paradigmas então construídos, e até mesmo o pensamento da tradição ocidental. Há aqui outra lei, que não é mais aquela da lógica da equivalência: a proporcionalidade entre pecado, morte e culpa está superada nesse momento. Trata-se da lógica do excesso, da vitória do sentido sobre o não-sentido, do Dom sobre o trágico, da Criação sobre o Niilismo. Quando pensamos em fundamentos primeiros da filosofia de Ricoeur, é possível considerar a ação e a linguagem como os dois núcleos de organização a partir dos quais sua reflexão se desenvolve. Tratam-se dos dois pontos principais que funcionaram como fio condutor de toda sua trajetória filosófica por meio de diversas tradições, tais como: filosofia reflexiva, hermenêutica, fenomenologia, analítica, psicanálise, etc. No entanto, nosso filósofo sempre deixa clara a diferença em relação à leitura crítica e à leitura confessante. A atitude hermenêutica filosófica de leitura livre e crítica dos textos se difere da leitura querigmática dos textos bíblicos. A teologia de que fala Ricoeur é compreendida pela nomeação de Deus e a palavra dita pelo homem em resposta. Ela considera a filosofia e não ousa traspassar limites, como, por exemplo, indagando “o que é Deus?”. Filosofia e teologia dividem um mesmo destino diante da retirada do nome de Deus; elas não podem surgir senão por um excesso de discurso, um discurso de segundo grau.

A maior aproximação entre filosofia e teologia no pensamento de Ricoeur encontra-se no tema da esperança. Trata-se do ponto de saída e o horizonte das duas disciplinas. A hermenêutica teológica tem como fundamento primeiro o querigma da fé e sua proposta é possibilitar um conjunto de conceitos à sua origem bíblica. Dessa forma, o querigma da esperança é de igual modo racional e irracional. Trata-se de um anúncio da ruptura inesperada de um acontecimento que está além da razão, e que é fonte da mesma. É a ruptura com uma antiga ordem e a inauguração de uma nova criação, possibilitando um novo 
horizonte na história, um novo ser.

Por outro lado, esse novo irracional faz pensar de forma diferente, desvelando-se em signos que podem ser pensados. Possibilita uma nova lógica, aquela da superabundância, que abre espaço, por exemplo, ao perdão:

Se é verdade que o querigma da Igreja primitiva centrava-se no acontecimento escatológico, então a totalidade da teologia deve ser interpretada segundo a norma da escatologia: a teologia não pode tomar como fio condutor a noção de logos ou de manifestação que fosse independente da esperança das coisas por vir, ou anteriores a ela. A tarefa de uma teologia da esperança consistiria em revisar todos os conceitos teológicos na base de uma exegese dirigida pela pregação do Reino por vir. (RICOEUR, 2006, p. 102).

Recolocada em uma teologia da promessa, a ressurreição aparece não como um evento que encerra a profecia completando-a, mas, sobretudo, como aquilo que permite uma abertura à promessa, confirmando-a. Contra as manifestações de um ser eterno, a teologia deve reinterpretar a ressurreição como um evento escatológico prometido a todos os homens na espera de uma nova criação. A linguagem dada a nós agita-se com diversos dons, e se inquieta com palavras de força donativa, como “dom”. A indeterminação é justamente o que permite a promessa, que, por sua vez, possibilita o perdão. A inquietação descreve os gemidos da história e da linguagem para produzir o evento da vinda do totalmente outro, do futuro imprevisível. A história e a linguagem movimentamse no ambiente da promessa, do espaço aberto entre o passado e o futuro.

Aqui se coloca a questão da relação entre alteridade e temporalidade na esperança. Um dos possíveis fundamentos da esperança é a promessa, palavra dada pelo outro. Palavra dada que pede minha confiança. Palavra dada no passado, na qual me apoio no presente, aberta a um devir não necessariamente melhor, que conheço pouco, exceto pelo fato de ser feito da mesma fidelidade daquele que o prometeu. A memória da promessa nutre a esperança. O tempo torna-se um amigo, pois é tecido pela promessa mantida do outro. Esse tempo amigo chama-se "história sagrada." (MIES, 2012, p. 144).

Não é de outra forma que saindo do face a face, através da memória, que posso me apoiar na promessa: ou seja, o face a face abriga um terceiro. Somente ele limita minha responsabilidade para com o outro, pois também sou responsável por ele. No entanto, ele não compôs esse espaço do terceiro, que esteve talvez certa vez diante de mim e que, por meio do dom e da promessa, fornece possibilidade de doar a minha vida pelo outro, como esperança. Diante da dinâmica do nome divino e da própria vivência, em seu primeiro livro póstumo, Ricoeur concluiu que a mediação de sua religiosidade pelo nome 
divino é um acaso transformado em destino por uma escolha contínua. Este acaso o fez cristão. Para o filósofo francês, cristão seria aquele que professa a adesão primordial à vida, palavras e morte de Jesus. Adesão entendida como a palavra grega Pistis. Ele adere à profundidade e ao mistério de Javé, nome que determina uma tradição e interpelação na vida, fazendo-o elaborar uma filosofia que vai da atestação à possibilidade, de modo que o acaso não é mero acaso, pois é assumido como escolha e transformado em continuidade pela esperança. É neste âmbito que acontece uma teologia do nome divino, sobretudo narrativa, que transmite um modo de ser, uma coragem de ser.

Dessa forma, ao teorizar sobre a teologia do nome divino, Ricoeur dá espaço à teologia narrativa ao invés de uma teologia dogmática, ou ainda uma ontoteologia sobre Deus. O nome divino porta metáforas que configura tradições plurais. $\mathrm{O}$ auge desta interpretação está na poética, que promove a compreensão do mundo diante do texto. A prática de vivência da fé do nome divino é transferida do texto para a vida. A essência poética possibilita refazer o mundo segundo a visada essencial da relação do sujeito com a narrativa bíblica. A palavra Deus torna-se uma expressão-limite que leva à experiência-limite, como, por exemplo, a superação da ética e do político para a mudança do mundo que é inaugurado pelo texto. O mundo que habitamos é refletido no mundo do texto, e o mundo do texto é a chave de acesso para o mundo habitado. Sendo assim, é pertinente analisarmos um contexto teológico historicamente situado, como aquele praticado na América Latina nas últimas décadas.

\section{UM NOVO HORIZONTE PARA A TEOLOGIA LATINO-AMERICANA}

Em suas raízes marxistas, a Teologia da Libertação negligenciou o corpo dos sujeitos vulneráveis. $\mathrm{O}$ pobre foi visto como aquele que deveria ser liberto, mas apenas em sua dimensão material-social. Nesse contexto, é muito significativa a afirmação de João Batista Libanio, na reunião da SOTER, em junho de 1990, de que a teologia enfrenta revisões importantes em suas formas de análise. A Teologia da Libertação, sobretudo, não pode ser prisioneira de conceitos restritos a classes sociais, sem aprofundar as realidades concretas das mulheres marginalizadas, das crianças abandonadas, dos indígenas dizimados, dos negros excluídos.

Ficou claro que tal marco não só necessita ser ampliado, como também revisto em profundidade por causa de suas insuficiências, entre elas, da hipertrofia da classe em detrimento de aspectos culturais e sexuais da realidade, da incapacidade de analisar as relações de poder na Igreja adaptando análises da 
macro sociedade, da carência de uma análise do estado, do desconhecimento de muitas novas realidades surgidas nesta nova fase do capitalismo etc. Aponta como caminhos um uso maior da antropologia social, da sociologia das instituições, de métodos quantitativos, da teoria da ação (LIBANIO, 1990, p. ? ).

Importante também é a abordagem do teólogo Hurtado, para quem a partir da kênosis, é preciso levar a sério todo o processo da encarnação história de Deus. "Por ela sabemos que a Encarnação não é algo neutro e genérico. É preciso afirmar, portanto, que somente observando o ser pobre de Jesus (e sua identidade com os pobres) podemos perscrutar o verdadeiro ser de Deus." (HURTADO, 2013, p. 97). Deus, em Jesus, mostra seu rosto concreto, sua carne pobre na qual historicamente revela o sentido antropológico e teológico mais profundo do ser humano. A totalidade da vida de Jesus não revela apenas quem Deus é, mas como ele age na história, sempre a partir do corpo concreto do outro, preferencialmente do mais pobre.

Por isso, a privatização de terras e a privatização de corpos fazem parte de um único sistema de desigualdade e sofrimento. A luta pelo direito a terra, por exemplo, e a luta pela dignidade do corpo, quando olhadas do ponto de vista de uma Teologia da Libertação atualizada, não podem ser separadas como se uma fosse resultado de trabalhadores sérios e a outra uma revolta histérica e burguesa. O projeto de uma sociedade justa e igualitária passa, necessariamente, pelo rompimento com o sistema heterocêntrico em todas as formas de reprodução do capital. Para a Teologia, as demandas das novas configurações sexuais não podem ser subjugadas à excessiva preocupação por uma libertação estritamente política e social. A contemporaneidade tem fundamental importância por desvelar que o homem não é apenas constituído de ideal, porém é feito de dores, de prazeres. E o pobre não é categoria abstrata, ele possui inscrições corpóreas que carregam as marcas da injustiça. Como afirma CARVALHAES (2010):

Talvez possamos iniciar uma nova procissão litúrgica com o pobre, carregando conosco um cálice transbordante de carências e desejos, potencialidades e misérias, contradições e desespero, traições políticas e pequenos gestos de redenção, morte e epifanias inesperadas do nosso dia a dia, tentando eternamente dar os contornos de uma graça perdida. E conforme caminhamos, atentaremos para o que sempre foi negado, esquecido, proibido e perigoso. Talvez, através dos líquidos e excreções teológicas do nosso corpo, beijos e sexualidades, representemos daqui em diante as subjetividades da nossa formação (CARVALHAES, 2010, p. 15).

De tal maneira que uma nova teologia pós-moderna deve buscar uma 
esperança possível, a partir do "novum do cristianismo como experiência de um triplo ultrapassamento: de si, do outro como inimigo e do mundo violento, como condição de possibilidade da instauração do Reino de Deus enquanto experiência salvífica de sentido realizado como reconciliação.” (MENDOZA, 2011, p. 219). E, ao que tudo indica, as novas configurações corpóreas são gramáticas existenciais indispensáveis também para novas reflexões teológicas, caso não queira insistir numa alteridade muito abstrata e ideal. Isso não significa descartar a iluminação especulativa, porém colocá-la a serviço da atualização de uma mensagem cristã que, mais do que um fato, configura-se sempre outra vez como uma ação salvífica de Deus na carne humana.

Em uma perspectiva moderna, a razão foi colocada no lugar de Deus. Mas o racionalismo demonstrou seu limite, pois ignorou dimensões importantes da existência humana, como, por exemplo, o religioso. O "sagrado" é esta vida presente, onde a esperança se manifesta.

A origem histórica da ideia da morte de Deus é dupla: metafísica e cristã, que convém distinguir, apesar da sua estreita ligação histórica. Dessa distinção dependerá o próprio destino do cristianismo, em contexto pós-metafísico; dela dependerá a resposta à questão de se:

[...] a ideia da morte de Deus conduz a metafísica e o cristianismo da mesma forma ao seu fim, de modo que, a partir do seu final comum, a metafísica e o cristianismo se tenham tornado, para sempre, idênticos; ou se b) a ideia da morte de Deus obriga a metafísica e o cristianismo a se despedirem um do outro de tal forma que se torne possível uma teologia cristã, não propriamente livre de metafísica, mas que assuma, frente à metafísica, uma atitude livre. (DUQUE, 2016, p. 97).

Ao afirmar uma existência de uma transcendência, ela só pode ocorrer na própria imanência. Dessa forma, alcançamos o estado de superação do sujeito metafísico, em um sentido moderno. Por outro lado, podemos afirmar que a "morte de Deus" não implica o fim da metafísica, mas sim de uma verdade absoluta, da certeza da apreensão da "coisa-em-si".

[...] a questão conduz precisamente ao centro de toda a teologia: pode esta continuar a ser teologia, integrando em si a morte de Deus? E pode ela permanecer teologia, ignorando-a? Nem um caso, nem o outro, desde que se esclareça o que se entende com esta forma de falar. A teologia terá que, por isso, compreender o que significa, no contexto do pensamento global, o discurso sobre a morte de Deus e avaliar o que significa o mesmo discurso em contexto especificamente teológico: o ponto de orientação será o problema que se esconde por detrás desse termo. (DUQUE, 2016, p. 97). 
Também Libanio ressalta a importância e as possibilidades abertas à teologia a partir do desconstrutivismo pós-moderno. Deus designa, assim, a diferença por excelência num mundo de subjetividades expostas e, ao mesmo tempo, ligadas por essa consciência niilista de desapossamento, abertura e, enfim, gratuidade e dom. O cristianismo, devido à sua lógica kenótica, é chamado a ser a consciência do ultrapassamento contínuo da religião, da teologia, da ciência, da técnica, da racionalidade absoluta como pretenso controle do mundo. Desse modo, é possível manter a condição apofática do discurso, da prática, dos desejos e das ações humanas, uma vez que elas estão profundamente marcadas por sua dissolução no nada:

A Pós-Modernidade presta excelente serviço à teologia fundamental, tornando-a mais criativa e aberta, já que insiste fortemente no caráter condicionado do conhecimento por causa da influência do tempo histórico, do lugar geográfico, da cultura de quem percebe a verdade. E daí as pessoas chegam a conclusões diferentes. Uma teologia fundamental rígida não dá conta desse traço consensual da cultura pós-moderna. O desconstrutivismo pós-moderno possui um sentido agudo e perspicaz para captar no interior dos sistemas e dos pontos de vista as contradições, as limitações e as debilidades, isolando-as e identificando-as. Denota o caráter de tentativa, de ensaio, de projeto inacabado, dos sistemas humanos de pensar. A teologia fundamental tem aí singular apoio à medida que ela assume tal posição diante dos pretensos absolutismos da Modernidade e de si mesma. Constitui-se, portanto, numa disciplina em permanente construção e sempre aberta a novas perguntas (LIBANIO, 2003, p. 169).

Uma indiferença fundacional instaura o sujeito em sua relação com o mundo, de forma que tal indeterminação indica a abertura da existência em sua gênese fenomenológica. A gênese da subjetividade pronominal virá em seguida para tentar ultrapassar essa indeterminação, com a finalidade de ensinar-nos a viver no mundo da vida. Mesmo assim, o nada permanece como a origem sem origem do devir, aquém de toda determinação de significação, de valor, de sentido e até de fundamento.

A teologia pós-moderna surge em fins do século XX como um arco-íris de experiências e de linguagens que buscam balbuciar o Mistério divino numa diversidade de expressões, de experiências e de contextos que corresponde à diversidade de subjetividades que vivenciam a presença amorosa e inovadora de Deus em suas micro-histórias. A narrativa de cada uma dessas subjetividades coletivas busca ser reconhecida, respeitada e promovida. Será preciso situar cada narrativa em sua própria cultura e subcultura, com base nos microrrelatos que gera, a partir dos quais é possível contar a fragmentada história da salvação. (MENDOZA, 2016, p. 304).

Derrida postula a desconstrução como o método próprio da ontologia 
enquanto renúncia à onipotência, para alcançar a consciência de si-como-outro no momento em que já se tornou presente para o espírito e para o corpo a finitude da labilidade humana. Diferença significa, assim, a afirmação de si mesmo pela deposição de si. Por esse motivo, Derrida propõe a diferença enquanto ação de abertura extrema, ilimitada, do si-mesmo para os outros. Jean-Luc Nancy, mais importante comentador de Derrida, propõe uma desconstrução do cristianismo segundo sua lógica da kénosis do Logos, com o conseguinte despojo da potência divina e do papel do cristianismo neste momento particular do ocidente. Cristo teria inaugurado assim a aguda consciência da agonia enquanto presença-ausência sempre atuante na metahistória.

Tudo sucede como se o cristianismo tivesse desenvolvido como nenhum outro o fez uma afirmação de poder, dominação e exploração teológico-econômicopolítica, da qual Roma seria o pesado símbolo e ao mesmo tempo uma parte da realidade, bem como uma afirmação inversa de despojo e abandono de si, cujo ponto de fuga seria o auto-desvanecimento. A questão deve ser então, naturalmente, a da natureza da estrutura desse auto-desvanecimento: ultrapassamento dialético, absolutamente novo... De uma maneira ou de outra, não se trata senão disto: como o monoteísmo se engendra como humanismo, e como o humanismo enfrenta a finitude que entrou assim na história. (NANCY, 2005, p. 60).

A postura mais autêntica torna-se uma existência niilista, enquanto é vivida nos limites de si mesmo. Uma existência vivida como tal por um sujeito vulnerável porque se confrontou por experiência própria com uma vida que não cessa de olhar de frente para a morte. $\mathrm{O}$ niilismo vivido ao extremo, enquanto possibilidade de um mundo outro, não o da Mesmidade, mas o da Diferença conduzida como vida até o final. Mundos aquém do fundamento, da significação, do sentido e do valor, convertidos em verdadeiros ídolos nos sistemas de totalidade. Um mundo, em última instância, de frente para o nada.

\section{CONSIDERAÇÕES FINAIS}

Novas gramáticas teológicas são constituídas sempre a partir das interpelações de cada tempo. A singularidade do evento cristão possui a importante vocação de ser fermento na massa, porque sua mensagem desenvolve-se a partir da convicção da revelação de Deus na história. No caso da pós-modernidade, seguramente uma de suas maiores reivindicações trata-se de uma ousadia hermenêutica em salvar a dignidade humana, tantas vezes asfixiada por princípios eternos que não levam em conta a singularidade de cada 
pessoa, de cada raça, cultura, língua. Ao aprofundar a condição humana radicalmente marcada pela historicidade, a presente reflexão mostrou como a vulnerabilidade corpórea traz novas demandas, sobretudo para a Teologia da Libertação.

Conclui-se, primeiramente, que uma teologia que considere as manifestações de uma corporeidade pulsional, ao mesmo tempo frágil e desejosa de construções novas, não pode se apegar, em absoluto, às suas categorias metafísicas, ainda que elas possam permanecer como pano de fundo dialógico. A primeira atitude seria a de uma escuta atenta de uma materialidade espiritual, mistério no qual o próprio divino habita. Ou seja, mais que o apego neurótico do que seja a essência do homem, a corporeidade pós-moderna revela que há uma ferida aberta, curada apenas no exercício de cada liberdade histórica, que pede à teologia a sensibilidade de um pastoreio honesto. Cuidado que faz sobretudo a partir da mística da Encarnação. Num segundo momento, a Teologia deve iluminar os cenários de vulnerabilidade, convocando-os, de maneira singular, ao empenho de superação do narcisismo que a própria fragilidade pode gerar. Por fim, os desfigurados da história devem ser escutados em seu protagonismo essencial quando são capazes de perdoar e guardar a esperança diante da ameaça da morte. Tal resistência não se encontra, hoje, nas sofisticadas construções epistemológicas, porém nas novas manifestações da corporeidade.

Concluindo, acredita-se que o paradigma da vulnerabilidade corpórea encontra-se ainda como nova gramática a ser aprofundada e que tenha desdobramentos importantes, apesar de imprevisíveis. No entanto, a esperança cristã proveniente da Encarnação do Verbo, deve produzir uma consciência nova que revele ao sujeito contemporâneo que sua carne é morada privilegiada da palavra, ainda que ela se encontre sempre nas fronteiras de sua finitude. Por isso, sua inteireza está decisivamente marcada por um dizer que possuiu um excesso de significado. É, certamente, como a liberdade vai lidar com esse resto pulsional, de um corpo que não é somente matéria, que definirá os destinos do sujeito e de sua cultura. Nesse ponto, a teologia contemporânea tem uma luz a oferecer, desde que também assuma sua palavra como vela humilde que ilumina a história humana, sempre em construção.

\section{REFERÊNCIAS}

ALISON, James. Fé além do ressentimento: fragmentos católicos em voz gay. São Paulo: É Realizações, 2010. 
BIRMAN, Joel. Mal-estar na atualidade: a psicanálise e as novas formas de subjetivação. Rio de Janeiro: Civilização Brasileira, 2001.

CARVALHAES, Cláudio. O pobre não tem sexo. In: Bíblia e sexualidade. São Paulo: Fonte Editorial, 2010.

DUQUE, João. Para um diálogo com a Pós-Modernidade. São Paulo: Paulus, 2016.

GIRARD, René. A violência e o sagrado. Rio de Janeiro: Paz e Terra, 1998.

GOSS, Robert. Jesus acted up. New York: Harper San Francisco, 1993.

HURTADO, Manuel. Deus, não sem nós: a humanidade de Deus para pensar Deus e os pobres. Reflexões em Eberhard Jüngel. São Paulo: Loyola, 2013.

LIBANIO, João Batista. América Latina: 500 anos de evangelização. São Paulo: Paulinas, 1990.

MENDOZA, Carlos-Álvarez. O Deus escondido da pós-modernidade. São Paulo: É Realizações, 2011.

MIES, Françoise (org.). Bíblia e filosofia: as luzes da razão. São Paulo: Loyola, 2012. MUSSKOPF, André. Via(da)gens teológicas. São Paulo: Fonte Editorial, 2012.

NANCY, Jean-Luc. La déclosion. Paris: PUF, 1997.

PIEPER, Frederico; MARASCHIN, Jaci (org.). Teologia e pós-modernidade. São

Paulo: Fonte Editorial, 2008.

RICOEUR, Paul. A Hermenêutica Bíblica. São Paulo: Loyola, 2006.

VATTIMO, Gianni. Credere di credere: è possibile essere cristiani nonostante la Chiesa? Milano: Garzanti, 1999.

VATTIMO, Gianni. La società trasparente. Nuova edizione accresciuta. Milano: Garzanti, 2000.

VATTIMO, Gianni. Depois da cristandade, por um cristianismo não religioso. Rio de Janeiro; São Paulo: Record, 2004.

VINCENT, Gilbert. La Réligion de Ricoeur. Paris: Les Éditions de l’ Atelier, 2008. 